\title{
Atividades motoras cotidianas e suas influências no desenvolvimento de pré-escolares
}

\author{
Maria Catarina Meirelles Faria* \\ Ana Lúcia Ratti Brolo** \\ Kelly Yukari Horita*** \\ Rute Estanislava Tolocka**** \\ Denise Castilho Cabrera Santos ${ }^{* * * * *}$ \\ Junior Vagner Pereira da Silva*****
}

\begin{abstract}
Resumo: Mudanças na estrutura social contemporânea podem influenciar o desenvolvimento infantil. Porém, poucos estudos têm investigado este fenômeno. $\mathrm{O}$ objetivo deste estudo foi analisar o cotidiano infantil de 38 crianças entre quatro e seis anos, frequentadoras em tempo integral de uma instituição de ensino, a sua interação com o meio ambiente em atividades lúdicas e as possibilidades de desenvolvimento. O cotidiano mostrou-se pobre em atividades fisicamente ativas; o meio ambiente da creche, rígido em sua rotina e inflexível com as atividades próprias das crianças. Porém, constatou-se que um evento lúdico pode propiciar atividades fisicamente ativas e enriquecer o meio ambiente. Palavras-chave: Pré-escolar. Atividades cotidianas. Desenvolvimento Infantil.
\end{abstract}

\section{INTRODUÇÃO}

Nas últimas décadas, a estrutura observada na sociedade contemporânea não tem sido das mais favoráveis para o desenvolvimento

\footnotetext{
* Mestranda em Educação Física da Universidade Metodista de Piracicaba (NUPEM/UNIMEP). Piracicaba, SP, Brasil. E-mail: catifaria@hotmail.com

** Mestre em Educação Física pela Universidade Metodista de Piracicaba (NUPEM/UNIMEP). Piracicaba, SP, Brasil. E-mail: albrolo@uol.com.br

*** Aluna do curso de graduação em Fisioterapia, da Universidade Metodista de Piracicaba. (NUPEM/UNIMEP). Piracicaba, SP, Brasil. E-mail: k.yuka@bol.com.br

${ }^{*}+* *$ Prof ${ }^{a}$ do Curso de Mestrado em Fisioterapia da Universidade Metodista de Piracicaba (NUPEM/UNIMEP). Piracicaba, SP, Brasil. E-mail: dcsantose@unimep.br

*** Prof. $^{a}$ do Curso de Mestrado em Fisioterapia da Universidade Metodista de Piracicaba (NUPEM/UNIMEP). Piracicaba, SP, Brasil. E-mail: dcsantose@unimep.br

Mestre em Educação Física pela Universidade Metodista de Piracicaba. (NUPEM/UNIMEP). Piracicaba, SP, Brasil. E-mail: jr_lazer@yahoo.com.br
} 


\section{Artigor Orifinais Maria Catarina Meirelles Faria et al.}

infantil. Conforme o exposto por Carlos Neto (2000a), Schwartz (2003), Matsudo et al. (2002), dentre outros, a urbanização e o desenvolvimento pós-industrial trouxeram grandes prejuízos ao contexto infantil, uma vez que locais como as ruas, que antes eram "habitadas" pelos jogos infantis, passaram a ser ocupados exclusivamente por veículos automotores. Este crescimento urbano desenfreado, em sua maioria sem nenhuma estruturação e planejamento arquitetônico, teve como consequência poucos locais reservados ao lazer e, como afirmou Marcellino (2002), tais mudanças sociais se tornaram verdadeiras barreiras para efetivação de um direito, o da criança, ao lazer e isto pode influenciar no seu desenvolvimento.

A idade com que a maioria das crianças vai para a escola tem diminuído desde 1996 (LIMA; BHERING, 2006) devido a transformações socioeconômicas, culturais e por políticas de educação infantil. As creches foram transformadas em instituições de ensino infantil. Além disto, a Lei $n^{\circ}$. 11.274 (BRASIL, 2006) aumentou para nove anos o Ensino Fundamental, colocando as crianças de seis anos nessa etapa do ensino, sem prévio preparo das escolas, o que altera o ambiente no qual a criança se desenvolve. Estar na escola diminuiu o tempo de convívio familiar (muitas crianças ficam o dia todo na escola) e com crianças de outras faixas etárias (na escola as crianças ficam a maior parte do tempo apenas com crianças que tem aproximadamente a mesma idade).

Embora o alvo desta modalidade de ensino seja o pleno desenvolvimento infantil (BRASIL, 1996) e o Referencial Curricular Nacional para a Educação Infantil (BRASIL, 1998) explicite o direito das crianças a brincar, reconhecendo esta ação como uma forma de comunicação e interação, as crianças podem permanecer nestas instituições entre nove e 10 horas diárias, com poucas oportunidades de brincar (BATISTA, 1998). Além disto, a maioria dos estudos relacionados à criança em ambiente de instituição de ensino infantil privilegia aspectos associados à nutrição e à exposição a processos infecciosos, responsáveis por grande parte das morbidades decorrentes da vida em coletividade, como por exemplo os estudos de Amorim e Rossetti (1999) ou Fisberg et al. (2004). Outros estudos relacionam-se à preparação dos profissionais que atuam junto a esta parcela da população, como os de

Movimento, Porto Alegre, v. 16, n. 01, p. 113-130, janeiro/março de 2010. 
Seguim e Daffre (2003), Maranhão (2000) ou Veríssimo e Fonseca (2003).

A importância da utilização de atividades lúdicas como mediadoras entre o conhecimento informal do universo cultural da criança e os conhecimentos formais da escola pode ser constatada pelo estudo realizado por Freire e Goda (2008), que através da proposição de uma oficina dos jogos, observaram, por exemplo, progressos no campo da moral, relações sociais, motricidade, afetividade, sensibilidade e estética. Para eles, estas atividades são adequadas para a educação, permitindo que a criança frequente a escola sem deixar de ser criança e produzem um espaço/contexto típico da infância.

Romera et al. (2007) investigaram a presença do lúdico na rede pública e privada, atentando-se para a aplicabilidade dessas atividades no dia a dia da escola, sua ligação com o processo de ensino-aprendizagem e a compreensão das professoras sobre o que seja atividade lúdica. As autoras concluíram que as professoras que trabalham com educação infantil conhecem o que é lúdico, reconhecem sua importância para o desenvolvimento da criança e a necessidade de sua vivência por parte delas; porém, a aplicação do lúdico de maneira intensa e ampla não é constatada ainda na maioria das ações observadas, o que é justificado, por exemplo, pelo excesso de conteúdo a ser desenvolvido em sala de aula, que ocasiona falta de tempo para essas atividades.

Outros estudos observaram como o meio ambiente/contexto das instituições de ensino infantil se relaciona com o desenvolvimento das crianças. Barros et al. (2003) verificaram que a utilização de brinquedos e os locais onde a criança permanece são inadequados para a faixa etária; ocorre falta de orientação pedagógica e de socialização extrafamiliar. Estes autores concluíram que o desenvolvimento das crianças biologicamente saudáveis pode sofrer influência negativa de fatores de risco ambientais.

De Marco (2006) verificou a interação da criança com o meio ambiente em aulas de Educação Física e atividades livres e sugeriu que atributos pessoais podem influenciar nas emoções demonstradas. Ela propôs que atributos positivos tais como curiosidade, interesse e engajamento nas atividades favorecem o aparecimento de sentimentos

Movimento, Porto Alegre, v. 16, n. 01, p. 113-130, janeiro/março de 2010. 
de alegria, enquanto os atributos pessoais negativos (impulsividade e desmotivação) trazem sentimento de frustração às crianças.

Esta autora notou também que o nível de habilidade motora da criança pode dificultar sua participação em determinada atividade, causando sentimentos como raiva ou tristeza, mas o sucesso nas atividades traz sentimentos de alegria e excitação. As aulas observadas foram na maioria das vezes, sob forma de comando, com o professor tomando a maioria das decisões, o que restringiu consideravelmente a possibilidade de criação das crianças em suas respostas motoras e consequentemente o desenvolvimento da autonomia nas mesmas, pois em momentos de atividades motoras livres as crianças demonstraram pouca criatividade e pequena autonomia.

Ramalho (1996), analisando crianças de cinco a seis anos em atividades espontâneas realizadas durante o recreio pré-escolar, constatou que este ambiente possibilitou poucas relações interpessoais, com atividades com pouco significado para as crianças e que não favorecia a vivência de papéis sociais diversos. Estes achados do contexto sociocultural não evidenciaram dinamicidade, adaptação progressiva, nem reestruturação do meio por parte da criança. Mas, investigando o recreio e a utilização dos espaços e equipamentos e os comportamentos de interação entre as crianças, Fernandes (2006) concluiu que os pátios escolares, nos quais há estímulos por parte da diversidade de materiais e espaços, proporcionaram interações bastante interessantes entre crianças com características diferentes das salas de aula, podendo ou não haver contato com crianças de outras faixas etárias para o desenvolvimento conjunto de brincadeiras.

Nascimento e Pellegrini (2004), também analisando o recreio escolar de crianças de 4/5 e 6/7 anos, verificaram que estes momentos são propícios ao desenvolvimento infantil, fornecendo oportunidades para as crianças organizarem, criarem e reorganizarem espaços e atividades, favorecendo interações sociais. Concluíram que as aprendizagens aconteceram a partir das interações sociais estabelecidas e nos momentos de exploração e descobertas espontâneas pelas suas próprias ações.

Movimento, Porto Alegre, v. 16, n. 01, p. 113-130, janeiro/março de 2010. 
Investigações como as acima relatadas, acerca das atividades realizadas pelas crianças em ambientes livres e lúdicos, atentaram para as características da estrutura física e dos materiais disponíveis para a criança brincar, bem como revelaram as diversas contribuições que estes podem ter para o desenvolvimento infantil, porém não discutiram se as crianças tinham aprendizagem prévia suficiente para brincar autonomamente em momentos livres.

Percebe-se que mudanças no meio ambiente podem estar restringindo as possibilidades da criança em se movimentar, mas são poucos os estudos que analisam o cotidiano infantil. Verifica-se também que as crianças que estão sendo levadas para as instituições infantis, em sua maioria não têm aulas que propiciem experiências de movimento ou que estas aulas podem estar sendo muito dirigidas, não favorecendo o desenvolvimento da autonomia e da criatividade. Nos momentos livres, algumas crianças se organizam, modificam o ambiente e participam de brincadeiras que podem favorecer seu desenvolvimento enquanto outras não o fazem, devido, provavelmente, à falta de vivências, desafios, estímulos, liberdade, afetividade, espaços e materiais adequados.

Assim, este estudo teve como objetivo verificar o cotidiano de crianças que permanecem em período integral em uma instituição de ensino infantil, bem como observá-las em um ambiente lúdico, realizado após um período de intervenção com aulas de Educação Física nas quais foram incentivadas e favorecidas aprendizagens de diversas brincadeiras, analisando se este contexto favorece o desenvolvimento.

\section{Aspectos METODOLÓGICOS}

\subsection{CARActerísticas da PESQUISA}

Trata-se de um estudo descritivo, realizado de acordo com os pressupostos da Teoria Bioecológica do desenvolvimento humano, proposta por Bronfenbrenner $(1992,2005)$, para observação da interação da criança e o contexto onde se insere, verificando características pessoais, isto é, disposições (curiosidade, iniciativa, empenho em atividades), recursos (destrezas e habilidades), demandas (capacidade de

Movimento, Porto Alegre, v. 16, n. 01, p. 113-130, janeiro/março de 2010. 
receber atenção, afeto ou despertar sentimentos negativos, lideranças positivas e negativas, dificuldade em cumprir as regras) e contexto (atividades que realiza, papéis sociais que assume e relações interpessoais de que participa).

\subsection{O LOCAL E OS PARTICIPANTES DO ESTUDO}

Foram observadas 38 crianças entre quatro e seis anos de idade, de ambos os sexos, frequentadoras de uma instituição pública de Ensino Infantil na periferia da cidade de Piracicaba-SP, em período integral, cujos pais assinaram um termo de consentimento livre e esclarecido. A escola possuía um parque com gangorra, balança suspensa, gira-gira e um salão pequeno e não oferecia aulas de Educação Física. A maioria das crianças provinha de lares com poucos recursos financeiros e com baixa escolaridade. O estudo foi aprovado pelo comitê de ética em pesquisa de uma universidade, com parecer $\mathrm{n}^{\circ}$. 61/06; a instituição concedeu autorização para realização do estudo.

\subsection{MATERIAL E MÉTODOS}

A rotina na escola foi fornecida pela direção através de um documento no qual constavam os horários e as atividades propostas para cada dia da semana.

Para análise do cotidiano infantil, foram coletadas informações sobre as atividades realizadas fora da escola, através da aplicação de um formulário para avaliação das atividades do cotidiano, adaptado de Silva et al (2004), com perguntas referentes a atividades realizadas no dia anterior e no último Domingo, sendo a coleta realizada entre terça e sexta-feira, individualmente, com cada pai ou responsável pela criança. Foi realizada a análise descritiva da distribuição dos dados.

A intervenção na rotina das crianças aconteceu a partir de um programa onde um professor de Educação Física ministrou 29 aulas, com duração de 40min, com dois encontros semanais para as classes do jardim I e jardim II A e B, separadamente. As crianças puderam aprender diversas brincadeiras com os seguintes materiais: lenços coloridos de TNT, bolas coloridas, tubos de papelão, petecas e pneus. As aulas foram registradas em um diário de campo, segundo Minayo (1996), contendo a descrição das atividades realizadas.

Movimento, Porto Alegre, v. 16, n. 01, p. 113-130, janeiro/março de 2010. 
Após estas aulas, estas crianças foram divididas aleatoriamente em quatro grupos e participaram de um evento (minicirco) com quatro estações de atividades e crianças de outras faixas etárias e escolas. Para fins deste estudo, foi escolhida apenas uma estação onde as crianças foram instruídas para brincar com os materiais livremente, tendo como restrição apenas o espaço, ou seja, as crianças deveriam permanecer apenas nesta parte da quadra (equivalente a $1 / 4$ do tamanho total da quadra) até o final das atividades, que acontecia após $15 \mathrm{~min}$ de seu início. Os materiais fornecidos foram tubos de papelão, lenços de TNT, bolas e petecas, dispostos no solo, lado a lado.

O evento foi registrado com duas câmeras digitais mini- DV, padrão NTSC (30 quadros por segundo). A primeira câmera foi fixada em um tripé com $1.36 \mathrm{~m}$ de altura e colocada na lateral do espaço de observação (quadra poliesportiva coberta), a $3 \mathrm{~m}$ de distância das atividades e a segunda câmera foi móvel, utilizando-se do recurso de zoom para capturar imagens aleatoriamente. Estas imagens foram transferidas para um computador com software da Pinacle Studio-Movie Box 9.4, para visualização quadro a quadro.

Estas imagens foram analisadas de acordo com os eixos interpretativos propostos por Bronfenbrenner (2005). Os registros foram feitos em uma tabela, contendo número da criança, interações sociais realizadas, atividades realizadas, material utilizado e papéis sociais assumidos.

\section{Resultados E discussão}

\subsection{COTIDIANO INFANTIL}

O horário de entrada das crianças na escola é entre $7 \mathrm{~h}$ e $8 \mathrm{~h}$ e o de saída, entre $16 \mathrm{~h}$ e $17 \mathrm{~h}$. Ao chegar, as crianças tomam café (durante 20min), logo após, são encaminhadas para a escovação dos dentes, que dura $10 \mathrm{~min}$. A seguir, participam de uma roda de conversa e de atividades dirigidas que duram aproximadamente $90 \mathrm{~min}$, quando então seguem para o parque para brincar por 40min. Após este período, as crianças são encaminhadas primeiramente para o banho e depois para o almoço. Depois da refeição, escovam novamente os dentes e seguem

Movimento, Porto Alegre, v. 16, n. 01, p. 113-130, janeiro/março de 2010. 
para o período de descanso, de sono, que dura cerca de $135 \mathrm{~min}$. Ao acordar, tomam leite e seguem para o momento de atividades de histórias e músicas. A seguir, inicia-se o período do jantar e depois escovam os dentes e aguardam a chegada dos pais ou responsáveis.

Nota-se, portanto, um processo que Pinto (2003) chamou de confinamento da infância, ou seja, as crianças permanecem trancadas nas instituições de ensino onde, diferentemente do espaço da rua, é o adulto que organiza o seu tempo e espaço e que define suas atividades e ações. Dormir é obrigatório mesmo que não se tenha sono, como também foi observado por Santos (2006), para quem a prática do sono, em instituições de Educação Infantil é uma atividade padronizada que repete modelos historicamente constituídos, sem respeitar as diferenças individuais com relação ao tempo de sono. As oportunidades de vivencias lúdicas são escassas nesta instituição, como também Romera et al. (2007) haviam constatado em outras instituições de Ensino Infantil.

Com relação ao cotidiano da criança fora da escola, constatou-se que o tempo médio de sono noturno da criança durante o dia da semana foi de $9 \mathrm{~h} 48 \mathrm{~min}$, com mínimo de $7 \mathrm{~h} 30 \mathrm{~min}$ e máximo de $12 \mathrm{~h} 30 \mathrm{~min}$. Assim, somando-se o tempo que a criança passa na escola com o tempo em que dorme fora dela, tem-se em média $19 \mathrm{~h} 23 \mathrm{~min}$, restando apenas $4 \mathrm{~h} 37 \mathrm{~min}$ para outras atividades extraescolares.

Fora da escola, as crianças gastam cerca de 106min durante a semana e 120 min no final de semana em atividades fisicamente ativas; nenhuma criança participa de escolas de esportes ou outras atividades com supervisão de um professor de Educação Física. A maioria das crianças gasta em média $283 \mathrm{~min}$ em atividades fisicamente passivas durante a semana e $323 \mathrm{~min}$ no final de semana, sendo a maior parte deste tempo utilizada para assistir TV pela maioria das crianças, tanto durante a semana quanto no domingo. A Tabela 1 ilustra o tempo médio e mediano gasto nestas atividades.

Portanto, o tempo médio gasto com as atividades fisicamente ativas é menor em relação às atividades fisicamente passivas, mostrando que estas crianças estão perdendo tempo e espaço para brincar ativamente, como também já havia sido relatado por outros estudos

Movimento, Porto Alegre, v. 16, n. 01, p. 113-130, janeiro/março de 2010. 
(CARLOS NETO 2000b; GAVARRY et al. 2003; STABELINI NETO et al. 2004; TOIGO, 2007). Assim, apesar de haver oportunidades para brincar também durante o final de semana, o tempo médio gasto com essas atividades (fisicamente ativas) continua ainda sendo menor em relação às atividades fisicamente passivas.

Diante destes resultados, constata-se uma distância ainda grande entre o que é considerado necessário para o desenvolvimento infantil, isto é, a prática de atividades fisicamente ativas, com o que é vivido na realidade pelas crianças em sua rotina diária dentro ou fora da instituição de ensino (GAVARRY et al. 2003; SILVA, 2006). A criança brinca, tem oportunidades de se movimentar, mas em tempo e espaço essas atividades fisicamente ativas ainda ocorrem em proporções menores do que as atividades fisicamente passivas, como também demonstraram os estudos de Carlos Neto (2000a; 2001b); Gavarry et al. (2003); Stabelini Neto et al. (2004) e Toigo (2007).

A criança precisa brincar, precisa se movimentar, mas são observados poucos momentos para que isso ocorra. Na instituição, este tempo é limitado aos 40 minutos de parque onde, muitas vezes, as atividades são dirigidas de acordo com a disponibilidade de equipamentos e rodízio de salas, fazendo com que as crianças tenham que "esperar" para brincar, bem como, em alguns casos, necessitam manter-se por perto, aos olhos da professora, sem poder correr, soltar-se e extravasar.

Com a introdução das aulas de Educação Física, as crianças passaram a ter $40 \mathrm{~min}$ de atividades fisicamente ativas, duas vezes por semana, o que ainda é pouco, perto da necessidade de se movimentar que esta faixa etária possui; outros momentos de atividades motoras poderiam ser oferecidos para elas na instituição. Nestas aulas, foram realizados 15 jogos e brincadeiras diferentes, sendo eles: Pega-Pega Rabinho (12 aulas), Tapete Mágico (12 aulas), Lenço Atrás (15 aulas), Pega-Pega Ajuda (9 aulas), Estátua (9 aulas), Acorda seu Urso (15 aulas), Estafeta (12 aulas), Corrida de Revezamento (12 aulas), Gato e Rato (12 aulas), Corrida de Cavalinhos (12 aulas), Equilibristas (12 aulas), Corrida dos Lenços (12 aulas), Cachorrinho e seu Osso (3 aulas), Salada de Frutas (6 aulas) e Serpente (3 aulas).

Movimento, Porto Alegre, v. 16, n. 01, p. 113-130, janeiro/março de 2010. 
122 Artifor Orifinais Maria Catarina Meirelles Faria et al.

No início do programa as crianças queriam correr por todo o espaço e demonstravam-se impacientes para escutar as instruções; ocorreram demonstrações de demandas negativas, tais como impulsividade, desmotivação, manifestações de raiva e agressividade, as quais foram diminuindo com o tempo. As crianças demonstraram aprendizagem de regras sociais, crescente controle das emoções, aumento de relações interpessoais e ganho de habilidade motora para realização das atividades.

\subsection{O DESENVOLVIMENTO DAS CRIANÇAS}

As atividades realizadas nas aulas de Educação Física proporcionaram interação com o meio ambiente que propiciou o desenvolvimento das crianças, que pode ser também observado quando elas mudaram para outro local, com diferentes demandas ambientais. De acordo com o pressuposto teórico assumido, a observação do desenvolvimento (BRONFENBRENNER, 2005) leva em conta quatro elementos: Processo (interações recíprocas e progressivamente mais complexas entre a pessoa e o meio ambiente); Pessoa (suas disposições, recursos e demandas); Contexto (ambientes que influenciam direta ou indiretamente a pessoa) e Tempo, os quais permitem observar modificações comportamentais.

Durante as aulas, puderam ser percebidas mudanças na interação das crianças com o meio ambiente, tais como o aparecimento e fortalecimento de relações interpessoais, que passaram de díadas ou tríadas (relação entre duas ou três pessoas) de observação para díadas ou tríadas de participação conjunta. Foram fortalecidas manifestações de demandas positivas tais como capacidade de receber atenção e afeto, lideranças positivas e disposições geradoras (curiosidade, iniciativa, empenho em atividades). Estas características se mantiveram no evento, onde se observou a manutenção das relações interpessoais e a manifestação destas demandas e disposições.

Durante o evento, foram verificadas 12 díadas de observação e 16 de participação conjunta, quatro tríadas de participação conjunta e quatro de observação. Dessas interações, foram observadas apenas duas díadas de observação entre as crianças deste estudo e as crianças da outra instituição.

Movimento, Porto Alegre, v. 16, n. 01, p. 113-130, janeiro/março de 2010. 
Para Bronfenbrenner (1996), a díade de participação conjunta constitui-se em duas pessoas que se percebem fazendo alguma coisa juntas, não necessariamente a mesma coisa, ao contrário, as atividades são diferentes mas complementares. Quando duas pessoas participam de uma atividade conjunta, é possível que desenvolvam sentimentos mais diferenciados e duradouros uma em relação à outra, tais como: reciprocidade (as atividades que um faz, influenciam as do outro, por isso têm de coordenar as atividades a partir também do outro), equilíbrio de poder e relação afetiva (desenvolvem sentimentos mais fortes de acordo com a progressividade da atividade).

No evento, as crianças brincaram de pega-pega, exploraram o material livremente, realizando atividades de manipulação e locomoção com um material ou com a combinação de dois materiais, dando a eles novos significados, realizando um total de 30 atividades diferentes, algumas vivenciadas nas aulas de Educação Física e outras não.

Algumas crianças se distanciaram do espaço demarcado por uma fita para explorar outros equipamentos presentes no local, criando diferentes atividades. Percebe-se que com materiais bastante acessíveis, elas desenvolveram inúmeras possibilidades de brincar. Além disto, elas ultrapassaram limites estabelecidos pela estação para percorrer outros espaços que foram atrativos a sua imaginação.

Observando a relação entre as atividades realizadas e as interações sociais estabelecidas, constata-se que as atividades que mais propiciaram interações foram as realizadas com os materiais tubo e bola. Isto pode ter ocorrido porque estes materiais eram previamente conhecidos das crianças, uma vez que brincaram com eles durante as aulas de Educação Física, oferecidas antes do evento. A facilidade de manuseio do material estimulou a expansão do brincar com ele e explorá-lo com outras crianças.

O número de relações interpessoais de participação conjunta foi maior que o número das relações de observação. Isto pode ter ocorrido porque nos momentos livres as crianças escolheram as atividades, os parceiros e os materiais; isto fez com que gostassem das atividades, aumentando o envolvimento nas mesmas. Também Coelho (2007), observando o comportamento de crianças durante a prática de ativi-

Movimento, Porto Alegre, v. 16, n. 01, p. 113-130, janeiro/março de 2010. 
dades motoras lúdicas, criadas pelas próprias crianças como resposta a situações-problema lhes apresentadas, constatou que as crianças se auto-organizam, modificando o ambiente e criando suas próprias atividades.

O predomínio de interrelações pessoais com crianças da mesma instituição pode ser justificado pelas poucas oportunidades que a criança tem de brincar com outras crianças, pois até mesmo na própria instituição a criança pouco convive com crianças de fora de seu círculo imediato (sala de aula). Esses resultados corroboram os achados dos estudos de Fernandes (2006) e Nascimento e Pellegrini (2004) que constataram que nos momentos de brincadeiras no pátio e no recreio, diversas interações ocorrem entre as crianças e propiciam que elas se auto-organizem, criando e reorganizando espaços e atividades.

Foi também observada a vivência de papéis sociais tanto no decorrer das aulas quanto no evento, tais como: equilibrista, jogador de futebol, lutador, varredor, cavaleiro e pintor. Aoportunidade de assumir diferentes papéis sociais auxilia a criança a compreender a dinâmica social em que está inserida, seja em um jogo na escola, seja em casa ou na sociedade de forma geral, percebendo e entendendo a sua posição frente às outras pessoas, bem como a posição das pessoas em relação a si. Os papéis sociais influenciam diretamente nas relações interpessoais estabelecidas pelas crianças, as quais ao assumir determinado papel social podem ter comportamentos a ele relacionados e alterar a dinâmica das relações estabelecidas (KREBS, 2009).

\section{CONSIDERAÇÕES FINAIS}

A realidade vivida pela criança nesta instituição de ensino não é das mais satisfatórias pois, apesar de ter supridas suas necessidades básicas (alimentação, higiene e sono), uma de suas necessidades fundamentais não está de todo sendo suprida, isto é, sua necessidade de brincar e de se movimentar, pois a instituição oferece apenas $40 \mathrm{~min}$ diários de atividade fisicamente ativa, e em média, fora da escola, elas podem brincar por mais $60 \mathrm{~min}$ ou $90 \mathrm{~min}$. Porém será que é suficiente? Acredita-se que não! A criança não é criança apenas 40min no dia,

Movimento, Porto Alegre, v. 16, n. 01, p. 113-130, janeiro/março de 2010. 
ela é criança em tempo integral e, por assim ser, é movimento o tempo todo.

A inserção de aulas de Educação Física trouxe contribuições ao desenvolvimento das crianças, oportunizando a vivência de papéis sociais, a formação de relações interpessoais, o fortalecimento de demandas positivas e disposições geradoras e a oportunidade de desenvolver habilidades que auxiliam no processo de criatividade; porém apenas $40 \mathrm{~min}$, duas vezes por semana é pouco e nem isto muitas instituições oferecem.

Através do brincar, movimentando-se, a criança explora, descobre, aprende, conhece a si e ao outro, experimenta situações diferentes; enfim, por meio de vivências lúdicas é que a criança é plenamente criança.

Todavia, a realidade encontrada demonstra que com seu tempo planejado, estipulado, demarcado e organizado pelo adulto, a criança é sufocada no que ela tem e é em sua essência, ou seja, movimento. Brincar transcende um direito legal da criança, compreende sua atividade principal e de maior relevância.

Mas o que fazer a partir dessa realidade? Sugere-se que nas instituições de Ensino Infantil mais espaços e tempo para a criança brincar sejam oferecidos, que seja também introduzida a educação para o lazer e não apenas através do lazer. Que mais eventos lúdicos e livres sejam elaborados e planejados na organização da instituição ou fora dela e/ou com outras instituições, pois foi verificado que através dessas atividades a criança cria, recria, explora, transforma e expande seus relacionamentos.

Outra sugestão seria respeitar as diferenças individuais em relação ao sono, oferecendo espaços e atividades para as crianças que não querem dormir durante o tempo para isto estipulado pela rotina da instituição. Seria interessante que as crianças pudessem optar em relação a algumas atividades realizadas no dia a dia, transformando momentos de atividades passivas em práticas fisicamente ativas que pudessem atingir os mesmos objetivos educacionais estabelecidos pelo adulto.

Movimento, Porto Alegre, v. 16, n. 01, p. 113-130, janeiro/março de 2010. 
126 Astifos Originais Maria Catarina Meirelles Faria et al.

Por fim, faz-se relevante também orientar e conscientizar os pais e/ou responsáveis através de palestras, oficinas e workshops para que também ajudem a oportunizar às crianças momentos de atividades lúdicas, mostrando a importância desses momentos para o desenvolvimento infantil.

Movimento, Porto Alegre, v. 16, n. 01, p. 113-130, janeiro/março de 2010. 
Daily living motor activities and their influences on the development of preschool

Abstract: Changes in the current social structure might influence the children's development. However, few studies have investigated this phenomenon. The aim of this study was to analyse activities of the daily lives of 38 children between four and six years old that spend full time in the child care center, their interaction with a playful environment and the possibilities of development. The daily life seems to be poor in physically active activities, the child's on day-care environment is rigid on its own routine and on the children's activities. However it was proved that a playful event can provide physically active activities and enrich the environment.

Keywords: Child. Preschool. Activities of Daily Living. Child Development.

Actividades motoras cotidianas y sus influen-
cias en el desarrollo
Resumen: Câmbios en la estructura social contempo-
ranea puedem impactar el desarrollo de los niños. Con-
tudo, mui pocos estudios han investigado esto fenomeno.
El objetivo del esto estudio fue analisar el cotidiano infanto
de 38 ninõs entre cuatro y seis anõs, frequentadores de
una escuela donde se quedavam todo el dia, sus inte-
raciones com el medio ambiente e las possibilida desar-
rollo. El cotidiano muestrase pobre en actividades fisica-
mente activas, el medio ambiente da creche es rigido y
su rotina y em las actividades propias de los niños. Con-
tudo fue demostrado que uno acontecimiento "lúdico"
puede propiciar las actividades fisicamente activas y
enriquecer el medio ambiente.
Palabras clave: Preescolar. Actividades Cotidianas.
Desarrollo Infantil.

\section{REFERÊNCIAS}

AMORIM, Katia; ROSSETI, Clotilde F. Análise crítica de investigações sobre doenças infecciosas respiratórias em crianças que frequentam creche. Journal of Pediatrics, Rio de Janeiro, v.75, n.5, p. 313-20, 1999.

BARROS, Karla Mônica F. T et al. Do environmental influences alter motor abilities acquisition? A comparison among children from day-care centers and private schools. Arquivos de Neuropsiquiatria, São Paulo, v.6, n.2-A, p. 170-75, 2003.

Movimento, Porto Alegre, v. 16, n. 01, p. 113-130, janeiro/março de 2010. 
128 Astifos Originais Maria Catarina Meirelles Faria et al.

BATISTA, Rosa. A rotina no dia a dia da creche entre o proposto e o vivido 1998. 175f. Dissertação (Mestrado) - Curso de Educação, Universidade Federal de Santa Catarina, Florianópolis, 1998.

BRASIL, Ministério da Educação. Lei de diretrizes e bases da educação nacional: artigo 29 da Educação Infantil. Lei no 9.394 de 20 de dezembro de 1996. Diário oficial da União, Brasília-DF, 1996.

BRASIL, Ministério da Educação e do Desporto/ Secretaria de Educação Fundamental. Referencial curricular nacional para a educação infantil, Brasília-DF, 1998. v. 3.

BRASIL. Lei $n^{\circ}$. 11.274 de 06 de Fevereiro de 2006: estabelece as diretrizes para o ensino fundamental de 9 anos. Diário oficial da União. Brasília-DF, 2006.

BRONFENBRENNER, Urie. Ecological Systems Theory. In: VASTA, Ross (Org.). Six theories of child development: revised formulations and current issues. London: Jessica Kingley, 1992.

A ecologia do desenvolvimento 1: experimentos naturais e planejados. Porto Alegre: Artes Médicas, 1996.

Making human beings human: bioecological perspectives on human development. London: Sage, 2005.

CARLOS NETO. A educação motora e as culturas de infância: a importância da Educação Física e desporto no Contexto Escolar. In: CONGRESSO LATINO-AMERICANO, 2, 2000, Natal, CONGRESSO BRASILEIRO DE EDUCAÇÃO MOTORA, 2000, Natal. Anais... Natal: UFRGN, 2000a. v. 3. 1 CD-ROM.

. O jogo e tempo livre nas rotinas de vida quotidiana de crianças e jovens. In: CÂMARA MUNICIPAL DE LISBOA. Departamento de ação social. Seminário de tempos livres: a criança, o espaço, a ideia. Lisboa: 2000b. p. 11-20.

COELHO, Vitor Antônio Cerignoni. Interrelações de diferentes aspectos do desenvolvimento da habilidade de arremessar por cima do ombro. 2007. 135 f. Dissertação (Mestrado) - Curso de Educação Física, UNIMEP, Piracicaba, 2007.

DE MARCO, Melissa Cecato. Manifestações emocionais em atividades motoras de crianças de $\mathbf{5}$ a 6 anos de idade da educação infantil. 2006. 130 f. Dissertação (Mestrado) - Curso de Educação Física, UNIMEP, Piracicaba, 2006.

FERNANDES, Odara de Sá. Crianças no pátio escolar: a utilização dos espaços e comportamento infantil no recreio. 2006. Dissertação (Mestrado) - Curso de Psicologia, Universidade Federal do Rio Grande do Norte, Natal 2006.

FISBERG, Regina Mara et al. Estado nutricional e fatores associados ao déficit de crescimento de crianças frequentadoras de creches públicas do município de São Paulo. Cad. Saúde Pública, Rio de Janeiro, v.20, n. 3, p. 812-17, 2004.

FREIRE, João Batista; GODA, Ciro. Fabricando: as oficinas do jogo como proposta educacional nas séries iniciais do ensino fundamental. Movimento, Porto Alegre,

Movimento, Porto Alegre, v. 16, n. 01, p. 113-130, janeiro/março de 2010. 
v.14. n.1. p.111-134, jan./abr. 2008. Disponível em: <http://www.seer.ufrgs.br/ index.php/Movimento/article/view/3762/2127>. Acesso em: 17 out. 2009.

GAVARRY, Olivier et al. Habitual physical activity in children and adolescents during school and free days. Medicine and Science in Sports and Exercise, v.35, n.3, p. 525-531, 2003.

KREBS, Ruy Jornada. Proximal processes as the primary engines of development. International Journal of Sport Psychology, New Jersey, v. 40, n. 1, p. 219-228, 2009.

LIMA, Ana Beatriz Rocha; BHERING, Eliana. Um estudo sobre creches como ambiente de desenvolvimento. Cadernos de Pesquisa, São Paulo, v. 36, n.129, p. 573-596, set./dez. 2006.

MARANHÃO, Damaris Gomes. O processo saúde-doença e os cuidados com a saúde na perspectiva dos educadores infantis. Cadernos de Saúde Pública, Rio de Janeiro v.16, n.4, p.1143-8, 2000.

MARCELLINO, Nelson Carvalho. Estudos do lazer: uma introdução. 3. ed. São Paulo: Autores Associados, 2002.

MATSUDO, Sandra Marcela Mahecha et al. Nível de atividade física da população do Estado de São Paulo: análise de acordo com o gênero, idade, nível sócio-econômico, distribuição geográfica e de conhecimento. Revista Brasileira de Ciência e Movimento, Brasília-DF, v.10, n.4, p. 41-50, 2002.

MINAYO, Maria Cecília. O desafio do conhecimento: pesquisa qualitativa em saúde. São Paulo: Hucitec, 1996.

NASCIMENTO, Cláudio Tarso; PELLEGRINI, Ana Maria. A aquisição espontânea de habilidades motoras no contexto da escola. Estudos em Avaliação Educacional, São Paulo, v.15, n.30, jul.-dez., 2004.

PINTO, Maria Raquel Barreto. A condição social do brincar na escola: o ponto de vista da criança. 2003. Dissertação (Mestrado) - Curso de Educação, Universidade Federal de Santa Catarina, Florianópolis, 2003.

RAMALHO, Maria Helena Silva. O recreio pré-escolar e a motricidade infantil na perspectiva da teoria da ecologia do desenvolvimento humano. 1996. Tese (Doutorado) - Curso de Ciência do Movimento, Universidade Federal de Santa Maria, Santa Maria, 1996.

ROMERA, Liana. et al. O lúdico no processo pedagógico da educação infantil: importante, porém ausente. Movimento, Porto Alegre, v.13, n.2, p.131-152, maio/ ago. 2007. Disponível em: <http://www.seer.ufrgs.br/index.php/Movimento/article/ view/3550>. Acesso em: 17 out. 2009.

SANTOS, Maria Goreti Miguel. A Educação Infantil frente aos diferentes padrões de sono e vigília de crianças de $\mathbf{0}$ a 3 anos: dilemas e equívocos. 2008. Dissertação (Mestrado) - Curso de Educação, Pontifícia Universidade Católica de São Paulo, São Paulo, 2006.

Movimento, Porto Alegre, v. 16, n. 01, p. 113-130, janeiro/março de 2010. 
130 Artifor Orifinais Maria Catarina Meirelles Faria et al.

SCHWARTZ, Gisele Maria. O conteúdo virtual do lazer: contemporizando Dumazedier, Centro de Estudos de Lazer e Recreação - CELAR. Escola de Educação Física, Fisioterapia e Terapia Ocupacional da UFMG. Licere, Belo Horizonte, v.6, n.2, p. 23-31, 2003.

SEGUIM, Cristina; DAFFRE, Silvia Gomara. Atendendo bebês a tempo: intervenções em um abrigo. Pediatria Moderna, São Paulo, v.39, n.3, p. 66-69, 2003.

SILVA, Junior Vagner Pereira. Crescimento, habilidades motoras básicas e cotidiano infantil de crianças de Campo Grande - MS. 2006. Dissertação (Mestrado) - Curso de Educação Física, UNIMEP, Piracicaba, 2006.

SILVA, Junior Vagner Pereira et al. Formulário de atividades de lazer para pré-púberes. In: ENCONTRO NACIONAL DE RECREAÇÃO E LAZER, 2004, Salvador. Anais... Salvador: UFBA, 2004. v.16, p.1-7. CD ROM.

STABELINI NETO, Antônio et al. Relação entre fatores ambientais e habilidades motoras básicas em crianças de 6 e 7 anos. Revista Mackenzie de Educação Física e Esporte, São Paulo, v.3, n.3, p.135-140, 2004. Disponível em: <http:// www3.mackenzie.br/editora/index.php/remef/issue/view/123> Acesso em: 17 out. 2009.

TOIGO, Adriana Marques. Níveis de atividade física na educação física escolar e durante o tempo livre em crianças e adolescentes. Revista Mackenzie de Educação Física e Esporte, São Paulo, v.6, n.1, p.45-56, 2007. Disponível em: <http:/ /www3.mackenzie.br/editora/index.php/remef/issue/view/119> Acesso em: 17 out. 2009.

VERÍSSIMO, Maria De La Ó Ramallo; FONSECA, Rosa Maria Godoy Serpa da. O cuidado da criança segundo trabalhadoras de creches. Revista Latino-americana de Enfermagem, Ribeirão Preto, v.11, n.1, p. 28-35, 2003.

Movimento, Porto Alegre, v. 16, n. 01, p. 113-130, janeiro/março de 2010. 